month includes a new cooperation project on coal technology. Bulgaria, while so far urging no major changes, is cautiously contributing to the energy debate by publishing statistics of $\mathrm{kW}-\mathrm{h}$ of lighting saved this year by "summer time".
Meanwhile, East Germany, although claiming that, in spite of the harsh winter conditions, planned production of electric power was "achieved as a whole after the first six months", did not allow the temporary setback to the economy to be entirely attributed to meteorological conditions. In June, a result of "shortcomings in management, especially in the ministerial sector for coal and power", Klaus Seibold, the Minister of Energy, was dismissed from of fice.

\title{
Spanish scientists have to fight for survival
}

Research in Spain is suffering from a lack of direction and funds. M Vicente, a Spanish biologist, reports on a recent meeting of scientists to discuss their plight and Emilio Munoz (below) reports on one ray of hope - the setting up of a new research ministry.

Uncertainty of direction, lack of promotion opportunities and no guarantee of long-term finance: these are the crucial problems that bedevil scientific research in Spain. They were given a public airing last month when biology and biomedical researchers met under the auspices of the CSIC (Consejo Superior de Investigaciones Cientificas). The scientists' intention was to test the reaction of the newly-created Ministry of Universities and Research (see below) to their complaints, and what emerged from the researchers amounted to a cry for survival.

The meeting had no difficulty agreeing that research policies were needed related to Spain's particular requirements. But they could not decide whether this was best approached through basic or applied research. One speaker said biology in Spain had concentrated on basic research for the past 15 years and all applied approaches had been treated as secondary. It was not surprising, he added, that there were no links between society and research and that, as a result, society was indifferent to the present scientific crisis. Other speakers defended basic research and argued that they were doing enough for society by teaching young scientists in the universities.

The second major theme of the meeting was that the country's scientific researchers were not only too few in number but also too old. The average age of Spain's scientific community was said to be around 48 and this restricted the job opportunities for young scientists. The number of young PhDs nearly doubled every four years but only one in five had a job related to his specialisation. Several causes were given for this situation, all with the same roots: the absence of long-term planning and the lack of interest in research.

Spain's scientific development during the 1960s happened at the wrong time and went in the wrong direction. The economy caught up with other developed countries, but largely because of imported foreign technology. A 10\%-a-year increase in public sector research staff was intended to accompany economic growth but never came into effect. Researchers in the private sector are even fewer and their work is limited to quality control. All these problems have now been aggravated by economic difficulties, so that Spanish research is coming of age at the worst possible time.

For scientists, the finance situation could be the most worrying of all. Because of its lack of social impact, research is not in the official list of priorities. Half way through the present year, research groups are spending the money assigned to them last year. No official programme of grants has been issued yet for next year. Unless urgent measures are taken, and experience of Spanish bureaucracy makes it unlikely that they will be, most scientists will have to stop their work early in 1980. Even strong groups, such as those in the Molecular Biology Centre in Madrid.

A secret three-year government plan to finance research was drafted a year ago. Its text is not known, raising suspicions among scientists that it will channel money to the increasingly overcrowded universities in which research has been so difficult that it tends to be the activity of a few dilettantes. They are afraid that a decision to transfer them to academic jobs will irreversibly damage their research activities.

\section{Will the new research ministry fill the vacuum?}

SpaIN has established a Ministry of Universities and Research - a move which has been welcomed by the scientific community. Scientists have felt that the lack of an effective government science policy has been paralysing efforts to build a new structure for research in Spain around the re-constituted Cosejo Superior de Investigaciones Cientificas (CSIC), and they hope the new ministry will fill the vacuum.

The Ministry of Universities and Research has been created by splitting the functions of the former Ministry of Education and Science, in which science had become submerged in the complicated problems of education. However, there are still fears that hopes for specific research proposals may again be disappointed. The government has not yet presented its research programme, so the reasons for the creation of the new ministry are unclear. And there is still a lack of communication between the scientific community and society. No national debate has taken place in parliament on this subject, although various sectors in the country have been demanding such a debate since 1977.

The need for a new ministry was established more clearly when the new statute of the CSIC was first put into practice. It was published in January 1978 and came into force the following June. It included a new system of government for the CSIC with the participation of collegiate bodies as advisory organs, and responsibility for the economic and scientific fields through the Scientific Council and Economic Council. This made real change in the CSIC a possibility. As with all the Spanish organisations during the time of the autocratic regime, CSIC had been conducted without any clear intent. However, the councils suffered many difficulties during their first months, due to a lack of scientific policy. The absence of any sign of a specific scientific policy has prevented a rational reorganisation of CSIC.

The reorganisation attempted by the CSIC so far has been mainly bureaucratic and administrative and is thus running the risk of becoming neither lively, dynamic nor relevant. However the Scientific
Council of CSIC has made imaginative efforts to amend its organisation. A document on the general trends of scientific policy in CSIC has been elaborated, which considers as fundamental that the activity of CSIC be adjusted to the needs of Spanish society and to the manpower and material resources of CSIC itself. The budget for 1979 allows 100 pta. (less than US \$2) per day per research worker for expenses of nonrecoverable material and this represents a significant improvement over 1978 !

Within the limited possibilities offered, CSIC has strived to overcome one of its main criticisms - its isolation from other research institutions. It is stressing agreements with universities and research institutions with the ultimate goal of resolving the existing academic power struggles. The Scientific Council of CSIC is trying to cooperate with the new Ministry of Universities and Research and recently asked for an interview with the minister with the aim of establishing contacts. 